\title{
A REFORMA TRABALHISTA E SEUS IMPACTOS NOS DIREITOS DOS TRABALHADORES
}

\author{
LABOR REFORM AND ITS IMPACTS ON WORKERS RIGHTS
}

\section{LA REFORMA LABORAL Y SUS IMPACTOS EN LOS DERECHOS DE LOS TRABAJADORES}

DOI: http://dx.doi.org/10.9771/gmed.v11i2.30476

\author{
Rachel Araujo Matos ${ }^{1}$ \\ Adriana Alves da Silva ${ }^{2}$ \\ Gleiciana Noronha Guedes ${ }^{3}$ \\ Liara Aparecida da Costa Fiusa ${ }^{4}$
}

\begin{abstract}
Resumo: O artigo discute a atual Reforma da Consolidação das Leis Trabalhistas, aprovada em 13 de julho de 2017, pela Lei $n^{\circ} 13.467$, onde se constata verdadeiro retrocesso social pela retirada de direitos há muito tempo conquistados, e a despolitização da classe trabalhadora ao destituir a contribuição sindical, fazendo com que o trabalhador não mais se sinta representado pelas suas organizações, provocando a alienação e fechamento de caminhos de luta. Defende a tese de que a classe trabalhadora nunca garantiu direitos sem luta e resistência e por isso é preciso não paralisar diante das perdas que já se efetivaram, mas lutar pelos direitos e emancipação de todos os brasileiros.
\end{abstract}

Palavras Chaves: Trabalho; Reforma Trabalhista; Direitos.

Resumen: El artículo discute la actual Reforma de la Consolidación de las Leyes Laborales, aprobada el 13 de julio de 2017, por la Ley $\mathrm{N}^{\circ} 13.467$ / 2017, donde se constata verdadero retroceso social por la retirada de derechos desde hace mucho tiempo conquistado y despolitización de la clase obrera al destituir a la clase trabajadora la contribución sindical, haciendo que el trabajador ya no se siente representado por sus organizaciones, provocando la alienación y el cierre de caminos de lucha. Defiende la tesis de que la clase trabajadora nunca garantizó derechos sin lucha y resistencia y por eso es preciso no paralizarse ante las pérdidas que ya se han hecho, sino luchar por los derechos y emancipación de todos los brasileños.

Palabras Clave: Trabajo; Reforma Laboral; Derechos.

Abstract: This article discusses the current Reform of the Consolidation of Labor Laws, approved July 13, 2017, by Law No. 13.467/2017, which reveals a real social retrocession for the long-term withdrawal of rights and depoliticization of the working class by dismissing the union contribution, making the worker no longer feel represented by their organizations, provoking the alienation and closure of ways of struggle. It defends the thesis that the working class has never guaranteed rights without struggle and resistance and therefore it is necessary not to paralyze before the losses that have already taken place, but to fight for the rights and emancipation of all Brazilians.

Keywords: Work. Labor Reform. Rights.

\section{Introdução}

Múltiplas são as causas da crise vivenciada no Brasil nos últimos anos. No plano político, destaques podem ser dados ao custo para manutenção dos poderes instituídos, a insegurança quanto à condução do país e a perda de credibilidade nas lideranças políticas constituídas de mandato eletivo, envolvidas em escândalos e processos de corrupção. No plano econômico, as maiores dificuldades 
enfrentadas reportam-se à recessão e ao desemprego que figuram em primeiro plano. No aspecto social constata-se o desmonte das políticas sociais e a perda de direitos já conquistados, resultantes de reformas como a trabalhista - Lei $\mathrm{N}^{\circ} 13.467$, aprovada em 13 de julho de 2017 - e a previdenciária - PEC 287/16 em curso no Congresso Nacional, cujo único beneficiário é o capital.

Todas essas crises têm impactado diretamente a vida dos trabalhadores provocando insegurança, medo e perda de direitos, historicamente conquistados. A Reforma Trabalhista, por exemplo, alterou mais de 100 pontos da Consolidação das Leis Trabalhistas - CLT (BRASIL, 1943), em vigor há mais de 60 anos - trazendo, ao invés de conquistas, retrocessos. Dentre as principais mudanças contidas na lei, observa-se a prevalência do negociado sobre o legislado, aprovação do trabalho intermitente, facilitação do trabalho de gestantes e lactantes em locais insalubres e dificuldade de acesso dos trabalhadores à justiça do trabalho. Todas essas novas regulamentações têm consequências diretas na vida do trabalhador que assiste ao paradoxo do crescimento do desemprego e a intensificação do trabalho, sem qualquer seguro e direitos trabalhistas.

A Reforma da Consolidação das Leis Trabalhistas tem como justificativas a falta de dinheiro, necessidade de equilíbrio das contas públicas, diminuição de impostos trabalhistas para a criação de mais postos de trabalho, dentre outras. Não obstante, o que se tem percebido, na prática, é o desmonte das conquistas históricas da classe trabalhadora, esvaziamento político do movimento sindical e a neutralização de suas reivindicações tais como a redução da jornada de trabalho sem redução de salário, participação dos empregados nos lucros das empresas, pagamento de horas extras etc., ou seja, é a legitimação da informalidade, da terceirização, enfim, precarização das condições de trabalho.

Essa realidade é consequência do processo de reestruturação produtiva ocorrida na década de 1990 quando se vivenciava, em âmbito mundial, um cenário de acirramento da competição intercapitalista e a revolução tecnológica, o que exigiu das empresas, para manterem-se "integradas economicamente à dinâmica capitalista mundial" (AMARAL; CESAR, 2009, p. 05), a implementação de mudanças em suas organizações a fim de a readequarem-se à nova realidade, situação que provocou alterações na forma e no ritmo de trabalho. Esse rearranjo do capital acentuou a precarização das condições laborais, impactou as relações de trabalho e reduziu os postos de trabalho, produzindo desemprego estrutural, com reflexos nos dias atuais.

Em verdade, essa realidade que tem como fundamento a "redefinição do processo de produção de mercadorias que deverá permitir e potencializar o desenvolvimento da dinâmica de acumulação" (AMARAL; CESAR, 2010, p. 07), traz consequências para a desrealização e quebra dos direitos dos trabalhadores, à medida que parte destes trabalhadores continua empregada, mas sofrendo pela adoção de padrões mais rígidos de controle do desempenho e parte, vivenciando o desemprego ou empregos precários, submetidos à jornadas extenuantes e formas de trabalho degradantes.

Assim, constata-se que o que está posto é uma "contrarreforma" contra a própria classe trabalhadora, visto que, diante de todas essas mudanças e com a expansão do capitalismo e a chegada do neoliberalismo, os trabalhadores, que já não tinham condições de trabalho e salários dignos, passam a sofrer com a perda de direitos, tornando-se esta perda mais contundente com a presença de um governo que 
trabalha sobre as bases de "reformas", colocando a classe trabalhadora, cada vez mais em situações de precarização, aumentando a jornada de trabalho e reduzindo salários (BOSCHETTI, 2010).

Mais do que isso, a reforma trabalhista confirma a superexploração do trabalhador quando preconiza, dentre outros aspectos, a mudança da jornada de trabalho de oito horas para até doze horas por dia, tendo o trabalhador que ocupar mais de um emprego para que possa ganhar o suficiente para sustentar sua família. Essa reforma configura-se portanto, como retrocesso social e retirada de direitos, além de contribuir para a despolitização da classe trabalhadora, haja vista destituir a contribuição sindical, fazendo com que o trabalhador não mais se sinta representado pelas suas organizações, abrindo caminhos para a alienação e, ao mesmo, tempo desmobilizando a luta coletiva e sindical e fortalecendo o espaço ocupado pelo mercado.

A realidade aqui apresentada nos instigou à reflexão, resultando no presente artigo que tem como objetivo investigar os rebatimentos da reforma trabalhista de 2017 (Lei nº13.467 de 13 de julho de 2017) nos direitos dos trabalhadores. Para o alcance desse objetivo, realizamos uma pesquisa bibliográfica que muito embora analise o já existente, nos iluminou na discussão da atual realidade, apontando novas reflexões e novas conclusões no processo de investigação sobre a relação entre trabalho e direitos na sociedade capitalista.

\section{Diretos: uma expressão controvertida na sociedade do capital}

De acordo com Boschetti (2010), historicamente o acesso aos direitos sociais, especificamente os direitos à seguridade social, estiveram condicionados ao acesso ao trabalho, com pagamento de contribuição fiscal. Nesse sentido, os direitos se regem pela lógica do seguro, garantidos por meio de contribuição anterior. Ante tal constatação, percebe-se que a materialidade dos direitos na sociedade, ao invés de produzir equidade, produz desigualdade, isso porque os sujeitos que não possuem emprego formal padecem com a falta de direitos.

$\mathrm{Na}$ verdade a lógica dos direitos, vista sob a ótica do seguro, demonstra a desigualdade entre os homens na sociedade de classe, uma vez que não leva em conta a vida e os indivíduos em suas relações concretas e densas de historicidade, mas apenas os fatores econômicos e as condições de possibilidade de pagamento. O seguro também escamoteia o indivíduo - ente a um só tempo, singular e genérico, e que não é somente um ser partícipe de uma espécie, mas também produtor de seu gênero e construtor da sociedade - quando lhe exige o pagamento do seguro e lhe nega o direito a todo o acervo e produção desta sociedade, quando este seguro não é pago.

A discussão dos direitos tem, dentre os autores de destaques, Karl Marx, que em sua obra Para a Questão Judaica (2009), ajuda-nos a entender o direito sob o ponto de vista da totalidade e superação do conflito entre a existência individual sensível do homem no seu cotidiano, que precisa de alimento, vestuário, abrigo etc., e a sua existência genérica, como ser social.

Em Para a Questão Judaica, Marx (2009) desromantiza o direito, mostrando que este é contraditório pois, para garantir a liberdade do homem, precisa do Estado como mediador. A obra é, na 
verdade, uma resposta aos escritos de Bruno Bauer publicados nos Anais Alemães em novembro de 1842. Tais escritos discutem a ausência de direitos dos judeus na sociedade alemã. $\mathrm{O}$ autor defende que num estado cristão, ninguém está emancipado e, reportando-se aos judeus, explica ser importante que estes, conservando-se como judeus, guardando seus dogmas e práticas religiosas, reivindiquem do Estado a abolição da exigência de uma filiação religiosa para o exercício de direitos, uma vez que o Estado não abdica de sua fé. Na concepção de Bauer, a solução para a questão judaica estava no ateísmo. Dessa forma, Estado e judeus deveriam renunciar à religiosidade em favor de um racionalismo, se quisessem que os direitos prevalecessem. Percebe-se portanto, que a questão dos judeus colocada por Bauer é limitada ao plano político civil e se resume ao aspecto religioso, ignorando a essência do Estado (MARX, 2009).

Assim, contestação de Marx a Bauer, é no sentido de este limitar a questão aos aspectos teológico da vida dos judeus, não ampliando a crítica para toda a sociedade. Conforme Marx, Bauer resolve a questão judaica pelo antagonismo religioso, propondo a solução do problema pela supressão da religião, esquecendo as relações sociais e despindo dessas relações os "estágios de desenvolvimento diverso do espírito humano" e, como assevera Marx, Bauer minimiza a questão e iguala e simplifica o processo de conquista de direitos “a cobras que largam a pele e passam a ter relação de igualdade” (MARX, 2009, pág. 41).

$\mathrm{Na}$ perspectiva do direito, Marx denuncia o direito como liberdade pois este, na sociedade de classe, "faz com que cada homem encontre no outro homem, não a realização, mas antes a barreira da sua liberdade" (MARX, 2009, p. 64). Com essa assertiva o autor contrapõe liberdade com propriedade - esta como direito de usurfruir da prórpria fortuna e dela dispor como quiser, por ser direito relativo exclusivamente ao interesse pessoal, sem qualquer atenção pelos outros homens. Assim, na sociedade de classe, a liberdade confunde-se com propriedade, e as duas cosntituem-se lados de uma mesma moeda. Por sua vez, o direito à segurança surge apenas como complemento de garantia da liberdade e da propriedade, depreendendo-se disso que os direitos do homem são direitos do homem egoista, por serem direitos relativos a interesses particulares e não a interesses coletivos. Assim, o direito na sociedade do capital é a garantia dos direitos do homem egoista que, por serem limitados, voltam-se explicitamente para os pressupostos do Estado Político.

Nesse sentido, Marx (2009) afirma que os direitos do homem na sociedade capitalista, ao invés de articular dialeticamente as dimensões individuais e genéricas dos cidadãos em direção à liberdade e à emancipação, serviram apenas como instrumento para demarcar, na sociedade burguesa, a individualidade e independência transformando-os em cidadãos atomizados, com interesses particulares e, por isso, egoistas, vivendo a condição de ser genérico de forma ilusória.

Isto significa que, fora da esfera pública, o homem age como simples indivíduo, ou seja, defende seus interesses particulares, privados e, portanto, interesses egoístas. Entretanto, para garantir que vai continuar usufruindo desses interesses, busca sua legitimação no Estado, a esfera da universalidade que, muito embora seja a responsável por afirmar esses direitos para todos, não elimina as diferenças efetivas que teimam em aparecer. 
Constata-se assim que, apesar do direito constituir dimensões relevantes na institucionalidade e na construção da cidadania na sociedade burguesa, em nenhum momento intenciona a plena emancipação ou o fim da desigualdade social, ao contrário, é mecanismo de legitimidade da ordem.

A obra Para a Questão Judaica ajuda-nos a compreender que, embora o objeto imediato de Marx (2009) seja as ideias de Bruno Bauer, sua crítica é mais ampla e dirige-se à limitação da emancipação política. O autor propõe uma emancipação humana fundada na relação dialética entre indivíduo e gênero, o que se realiza quando o ser genérico, restituido ao individuo na sua vida cotidiana, no trabalho e nas suas relações individuais, tiver se tornado efetivamente um ser genérico.

Ainda na referida obra, Marx explica que o caminho da emancipação humana passa, necessariamente, pela emancipação politica. Nesse sentido, mesmo limitados do ponto de vista de emancipação humana, em nenhum momento pode-se desconsiderar quão sinificativos são os direitos e sua materialização para a classe trabalhadora. Mesmo contraditório, o direito materializado garante o acesso aos serviços públicos e ao exercício democrático da cidadania.

Ressalte-se que há uma distância considerável entre a emancipação política e a emancipação humana, pois quando conquista-se direitos políticos, fruto da luta da classe trabalhadora, não significa rompimento com a sociedade vigente, pelo contrário, o direito político dá possibilidades para a manutenção da sociedade capitalista. Portanto, a efetivação de direitos não instaura uma nova sociabilidade mais justa e igualitária, mas sim a manutenção da ordem vigente, carecendo que a luta pelos direitos políticos possa ir para além deles, com destino à emancipação.

\section{Direitos e Reforma Trabalhista Brasileira}

Acreditando que o caminho para a emancipação humana passa, necessariamente, pela emancipação política, a luta pelos direitos na sociedade capitalista não se faz em vão, pois é pelo fortalecimento desta luta que se pode garantir a universalização destes e a conquista de parte da riqueza social gerada pelos trabalhadores (PANIAGO, 2003).

Com efeito, os direitos refletem as contradições de um confronto irreconciliável entre o capital e o trabalho e conquistá-los, não se faz de forma simples e harmoniosa, mas pela resistência e luta dos trabalhadores organizados que "arrancam" dos capitalistas ou "forçam" o Estado a se antecipar e a conceder direitos, implicando, num ou noutro caso, na promulgação de leis que regulamentam sua outorga e que, em sua maioria, materializam-se na forma dos benefícios indiretos assegurados pelas políticas sociais (PANIAGO, 2003).

A respeito da possibilidade de conquista e universalização dos direitos, constata-se que na atualidade, sob os efeitos da ofensiva neoliberal, estes vêm sendo limitados, reduzidos e retirados, como é o caso dos direitos suprimidos pela reforma da CLT- Consolidação das Leis Trabalhistas Brasileira (BRASIL, 1943), pela Lei n 13.467/2017, sancionada aos 13 de julho de 2017 (BRASIL, 2017). 
Para entender a reforma da CLT - Consolidação das Leis Trabalhistas Brasileira é necessário perceber que ela não está deslocada das mutações no mundo do trabalho, decorrentes de inúmeros fatores inclusive, da crise estrutural do capital.

Em verdade, as mudanças ocorridas e que vêm ocorrendo no mundo do trabalho, nos direitos e na própria ideologia que as sustentam, não estão deslocadas da crise da década de 1970, marcada pela forte presença do capital financeiro, tendo como representante um Estado neoliberal que estar para o capital e não para a classe trabalhadora. Nesse sentido, pode-se afirmar que o Estado tem sido utilizado pelo sistema como um instrumento afiançador dessas transformações.

Ressalta-se que, sendo o capital financeiro dependente da esfera produtiva, esta se modifica, passando da acumulação rígida representada pelo fordismo, para um regime de acumulação flexível, representado pelo Toyotismo. Esse modelo de produção traz, em seu bojo, a "flexibilização" das relações de trabalho, tornando-as cada vez mais precarizadas, resultando assim no crescimento das expressões da questão social e no ataque direto aos direitos sociais (ANTUNES, 2014).

Segundo Antunes (2014), foi na década de 1980 que a reestruturação produtiva do capital começou a se moldar no Brasil, adensando, no contexto da década de 1990, características da antiga forma de acumulação com a atual, ou seja, atualizando elementos do fordismo ao toyotismo. Essas configurações combinam-se com o ataque aos direitos sociais, via flexibilização e desregulamentação, com destaque para a presença da terceirização e precarização do trabalho.

No cenário brasileiro, após um longo período de ditadura e de duras lutas da sociedade civil organizada, tem início o período de redemocratização do Estado, porém, foi com a promulgação da Constituição Cidadã de 1988 que muitos direitos sociais foram garantidos, como por exemplo, o direito á saúde e à assistência social. No entanto, a presença mais intensa da reestruturação produtiva e do Estado neoliberal - que priorizou os ajustes em função da política econômica - impediram a materialização efetiva do que foi conquistado na Carta Constitucional, ou seja, com os acontecimentos da década de 1990, as políticas públicas sociais não saíram da formalidade.

Essas mudanças têm como principal objetivo atender aos interesses do capital e que, embora tenham dado trégua nos anos 2000, na atualidade ressurgem com mais força, impactando negativamente a vida e os direitos da classe trabalhadora que, para sobreviver, necessita vender sua força de trabalho. Ressalte-se que esse impacto atinge todos os trabalhadores: formais, informais e desempregados, que ficam à mercê da sociedade do modo de acumulação adotado. Contudo, o maior desmonte dos direitos trabalhistas - duramente conquistados pela classe trabalhadora brasileira - está em curso, graças à última reforma da CLT- Consolidação das Leis Trabalhistas, que coloca a (o) trabalhadora (o) em situação de vulnerabilidade social, haja vista a dificuldade de acesso e a restrição da cobertura dos seguros sociais.

A reforma trabalhista brasileira incide, dentre outros direitos, na forma de contratação, haja vista assegurar a prestação de serviços de forma descontínua, o que caracteriza trabalho intermitente. Assim, o contrato de trabalho deixa de ser indeterminado e o trabalhador, que antes era contratado para assumir uma tarefa contínua, agora passa a ser contratado para prestar serviço de forma descontínua e recebendo o pagamento apenas pelas horas trabalhadas (GALVÂO, et al 2017). 
Embora haja a justificativa de que a instituição do trabalho intermitente possa gerar novos empregos, ela mascara a desrealização e qualidade do trabalho bem como da vida do trabalhador, pois este passa a ficar disponível, 24 horas por dia, à espera de um contratante para dispor de sua força de trabalho e lhe avise da atividade laboral com 3 dias de antecedência, pagando apenas pelas horas trabalhadas. Como expresso no Dossiê da Reforma Trabalhista (GALVÃO et al 2017, pág. 35), “o trabalhador torna-se responsável por gerenciar sua sobrevivência na instabilidade", sendo portanto, culpabilizado e discriminado quando, por algum motivo, não aceitar o trabalho oferecido.

A terceirização é outro ataque aos direitos dos trabalhadores pois, pela Lei 13.429/2017, abre-se a possibilidade deste tipo de contrato para todas as atividades da empresa, sejam elas meio ou fim. $\mathrm{Na}$ realidade, a terceirização rompe com os vínculos trabalhistas, deixando o trabalhador vulnerável e inseguro, submetendo-se inclusive a tarefas extra instituição para não perder o emprego (BRASIL, 2017).

Outra quebra de direito conquistado refere-se à obrigatoriedade do intervalo de duas horas para refeição que, pelo novo estatuto legal, pode ser substituído por uma indenização e tempo mínimo de trinta minutos para o almoço. Sendo a lei para todos, na prática percebe-se que não são levados em conta os diversos tipos de trabalho e os riscos à saúde do trabalhador, uma vez que muitos trabalham em pé, por longos períodos e realizando atividades repetitivas ou em regime de plantão, realidade que os deixa vulneráveis a problemas ergonômicos ou lesões por esforços repetitivos. Além do mais não considera que o horário de almoço não é apenas para alimentar-se, mas também para descansar o corpo (NAVARRO, 2017).

Outra mudança trazida pela reforma trabalhista incide na vida das mulheres grávidas ou lactantes. Antes da reforma, a CLT previa, em seu artigo 396, que a mulher tinha direito a amamentar duas vezes ao dia por um intervalo de 30 minutos até o bebe completar seis meses. Com a nova lei, o tempo de intervalo, assim como sua frequência, deverá ser negociado com o empregador.

No tocante às demissões, a vida laboral das trabalhadoras grávidas ou lactantes também foi impactada. Anterior à reforma, não havia um período determinado para avisar ao empregador sobre situação de gravidez, assim, em caso de demissão, a mulher grávida cuja concepção do bebê tivesse acontecido enquanto empregada, poderia ser readmitida em qualquer tempo, com exceção apenas para quem já estava cumprindo aviso prévio, período de experiência ou trabalho temporário. Com a nova lei, caso seja demitida, a mulher tem apenas 30 dias para avisar que está gravida e, caso isso não aconteça, a demissão pode ser efetivada. Com tal mudança é possível inferir que a lei não considera as realidades vivenciadas por muitas mulheres trabalhadoras, haja vista nem sempre serem alcançadas pelo SUS no primeiro trimestre de gravidez, tampouco terem acompanhamento contínuo e regular, como deveriam, por um ginecologista obstetra. Tudo isso impede ou ao menos dificulta a confirmação da gravidez no período estabelecido pela lei, impossibilitando a trabalhadora de ter revista a sua demissão.

Quanto à permanência em lugares insalubres, o Art. 394-A \ $3^{\circ}$ da nova lei, assevera que o trabalho de mulheres grávidas ou lactantes em lugares insalubres é permitido, podendo a mulher ser afastada quando o médico assim recomendar: “A empregada lactante será afastada de atividades e operações consideradas 
insalubres em qualquer grau quando apresentar atestado de saúde emitido por médico de sua confiança, do sistema privado ou público de saúde, que recomende o afastamento durante a lactação" (BRASIL, 2017).

A nova lei também altera os procedimentos para a dispensa do trabalhador. Segundo o Art. 477 - A, a demissão do trabalhador não mais precisará da homologação do sindicado nem de celebração coletiva; complementando o disposto, o Art.484 - A, afirma que a rescisão do contrato de trabalho pode se dar por acordo, onde o trabalhador recebe o aviso prévio e a indenização sobre o saldo do FGTS, podendo movimentar $80 \%$ deste e não mais tendo direito a ingressar no Programa Seguro Desemprego.

Como já dissemos, a reforma modificou mais de 100 artigos da CLT, o que não nos permite fazer uma análise de cada um, devido à quantidade. No entanto, como nosso objetivo foi investigar os rebatimentos da reforma trabalhista de 2017 nos direitos dos trabalhadores, para fomentar a reflexão e a discussão, explicitá-los aqui foi necessário para maior compreensão do significado desta reforma no que se refere à perda de direitos, tão arduamente conquistados.

Seguramente, a reforma trabalhista é uma resposta às exigências do capital que, ávido por lucros, impõe a redução dos custos da produção com implicações diretas na vida dos trabalhadores: maior exploração, ampliação das formas flexíveis de trabalho (informais, subcontratados, terceirizados etc.), aumento expressivo do desemprego, dentre outros, numa lógica de supressão dos direitos historicamente conquistados (BEHRING, 2008).

\section{Conclusão}

As reflexões produzidas no presente artigo demonstram que a reforma trabalhista brasileira sob a Lei $n^{\circ}$ 13.467/2017 sancionada pelo Presidente Michel Temer, aos 13 de julho de 2017, revela-se como parte das medidas liberalizantes do governo e passa longe de promover a realização e qualidade de vida do trabalhador. Assentada na perspectiva de criar um ambiente institucional favorável tanto para o capital produtivo como para o rentismo, a reforma assegura ao primeiro, a possibilidade de reduzir custos por meio da ampliação da flexibilização do trabalho e ao último, a rentabilidade via redução dos gastos públicos, restando ao trabalhador as inseguranças do mercado e a precarização do trabalho.

A Reforma Trabalhista, associada à outras reformas já implantadas ou em curso, revela seu caráter perverso, tendo em vista sua sansão ter sido imposta e sem qualquer discussão com a classe trabalhadora, mascarando assim seus reais objetivos, quais sejam: redução de investimentos nas políticas sociais; desvio de recursos da seguridade social para pagar juros e amortização da dívida pública; fragilização das leis trabalhistas e regressão de direitos da classe trabalhadora; sucateamento dos serviços públicos e fortalecimento do setor privado rentista, entre outros. Tudo isso beneficia a lógica neoliberal presente na sociedade brasileira e, consequentemente, o capital financeiro.

A Reforma Trabalhista revela ainda a perda de direitos do trabalhador uma vez que, flexibilizando a contratação e a jornada de trabalho, reduz a carga tributária dos empregadores, diminuindo a arrecadação e, por consequência, o tamanho do Estado e das políticas sociais. Isso significa que quanto menor a presença 
do Estado via políticas sociais, maior a abertura de espaços para a iniciativa privada ofertar tais serviços, comprometendo a universalidade e a equidade, bem como os direitos dos trabalhadores.

Poderíamos depois dessa reflexão nos questionar: "o que nos resta?" "Aceitar todos esses retrocessos?" "Resistir e lutar pelos direitos presentes nas páginas da Constituição Federal, mas que não se efetivam da mesma forma, na prática?”. Não temos uma resposta filosofal para tais reflexões, todavia, buscando luzes no passado para que nos ilumine no futuro, percebe-se que a classe trabalhadora nunca conquistou direitos sem luta e resistência. Por isso é preciso não ficar paralisados diante das perdas já efetivadas. É preciso luta e resistência pela garantia dos direitos que pertencem à classe trabalhadora.

\section{Referências:}

AMARAL, Ângela Santana do; CÉSAR, Mônica de Jesus. O trabalho do assistente social nas empresas capitalistas. In. CFESS/ ABEPSS/ CEAD-UnB. Pós-Graduação Latu Sensu em Serviço Social: direitos sociais e competências profissionais. Brasília: CEAD/UnB, 2010.

ANTUNES, Ricardo. A nova morfologia do trabalho e as formas diferenciadas de reestruturação produtiva no Brasil dos anos 1990. Sociologia. Revista da faculdade de Letras da Universidade do Porto Vol. XXVII, 2014 pág. 11-25.

BEHRING, Elaine. Brasil em Contra-Reforma: desestruturação do Estado e perda de direitos. 2 ed. São Paulo: Cortez, 2008.

BOSCHETE, Ivanete S. Seguridade Social no Brasil: consequências e limites a sua efetivação. In. CFESS/ ABEPSS/ CEAD-UnB. Pós-Graduação Latu Sensu em Serviço Social: direitos sociais e competências profissionais. Brasília: CEAD/UnB, 2010

BRASIL. Decreto-Lei $N^{\circ} 5.452$, de $1^{\circ}$ de maio de 1943. Aprova a Consolidação das Leis do Trabalho. Rio de Janeiro, 1943. Disponível em: http://www.planalto.gov.br/ccivil 03/decreto-lei/Del5452.htm. Acesso: 15.11.2018.

BRASIL. Lei N¹3.467, De 13 de julho de 2017. Altera a Consolidação das Leis do Trabalho (CLT), aprovada pelo Decreto-Lei ㄲo5.452, de 1o de maio de 1943, e as Leis no 6.019, de 3 de janeiro de 1974, 8.036, de 11 de maio de 1990, e 8.212, de 24 de julho de 1991, a fim de adequar a legislação às novas relações de trabalho. Brasília, DF, 13 de julho de 2017. Disponível em:

http://www.planalto.gov.br/ccivil_03/_ato2015-2018/2017/lei/L13467.htm. Acesso: 15.11.2018.

GALVÃO. A. et al. Dossiê reforma trabalhista. Campinas, Cesit/ie/Unicamp. Disponível em: http://www.cesit.net.br/dossie-reforma-trabalhista/. Acesso: 31.07.2017.

MARX, Karl. Para a questão judaica. São Paulo: Expressão Popular, 2009.

NAVARRO, Vera Lúcia. Reforma Trabalhista: é muito atraso, é muito retrocesso. Entrevista. Revista Adital. 13 de novembro de 2017. São Leopoldo. RS. Disponível em: http://www.ihu.unisinos.br/186noticias/noticias-2017/573562-reforma-trabalhista-e-muito-atraso-e-muito-retrocesso. Acesso:

15.11.2018.

PANIAGO, Maria Cristina Soares. As Políticas Sociais, as lutas defensivas do Welfare State e a luta histórica pela jornada de trabalho de 10 horas - contribuições problemáticas à luta pela emancipação do trabalho. X Congresso Brasileiro de Assistentes Sociais, Rio de Janeiro, RJ, 2001. Disponível em: http://www.cristinapaniago.com/yahoo site admin/assets/docs/As Politicas Sociais as Lutas Defensi vas do_Welfare_State_e_a_Luta_Historica_pela_Jornada_de_Trabalho_de_10 horas.185201853.pdf. Acesso: 15.11.2018.

\section{Notas:}


${ }^{1}$ Discente do curso de Serviço Social no Instituto Federal de Ciência e Tecnologia-IFCE. ORCID: https://orcid.org/0000-00033094-6051 Email: rachel.araujoo@,outlook.com

${ }^{2}$ Docente do curso de Serviço Social no Instituto Federal de Ciência e Tecnologia-IFCE. ORCID: https://orcid.org/0000-00018467-5889 Email: adriana.as.ce@gmail.com

${ }^{3}$ Discente do curso de Serviço Social no Instituto Federal de Ciência e Tecnologia-IFCE. ORCID: https://orcid.org/0000-00030296-7015 Email: gleicinhaguedes15@gmail.com

${ }_{4}^{4}$ Discente do curso de Serviço Social no Instituto Federal de Ciência e Tecnologia-IFCE. ORCID: https://orcid.org/0000-00033650-4131 Email: liaranicolasfiusa04@gmail.com

Recebido em: 24/03/2019

Aprovado em: 16/09/2019 